EMERITA. Revista de Lingüística y Filología Clásica (EM)

LXXV 2, julio-diciembre de 2007

pp. 199-224

ISSN 0013-6662

\title{
ESTUDIO CRÍTICO-TEXTUAL DEL LIBRO III DE NA DE CLAUDIO ELIANO: NORMATIVISMO Y CUESTIONES DE MÉTODO PARA LA EDICIÓN DE LA OBRA
}

\author{
MANUELA GARCÍA VALDÉS \\ Universidad de Oviedo
}

\begin{abstract}
La autora de este artículo lleva a cabo un estudio crítico textual de los principales pasajes discutibles del libro tercero de De natura animalium (NA) de Claudio Eliano (III 2.60.20-24; III 3.60.27; III 18.67.12-13; III 21.68.1; III 22.69.7-10; III 23.69.17-20; III 26.71.23; III 26.71.28-9; III 38.75.29; III 42.77.15 y III 44.77.27). En el análisis, ha intentado demostrar, por un lado, el desconocimiento que se tiene aún de la lengua de Eliano para comprender bien su texto, eliminar correcciones y enmiendas que han sido hechas arbitrariamente por anteriores criticos y editar la obra; por otro lado, desarrolla y aplica las líneas metodológicas crítico-textuales principales: los textos literarios de la koiné requieren un tratamiento rigurosamente diferenciado, teniendo en cuenta la corriente literaria de la época, la evolución y el uso de la lengua, sus peculiaridades fonéticas, morfológicas y sintácticas de la prosa griega tardía, y el uso del autor. Sin embargo, se ha seguido juzgando y analizando su obra teniendo en cuenta la normativa del griego clásico. La investigación es una nueva contribución al conocimiento de la lengua de Eliano, del griego postclásico y de la ecdótica para textos griegos de la época imperial.
\end{abstract}

Palabras-clave: Crítica textual. La lengua de De natura animalium de Eliano. La lengua de la koiné griega tardía. Líneas metodológicas crítico textuales principales. Écdosis de la obra de Eliano y de otros textos de la época imperial griega.
The authoress of this paper develops a critical study on the main debatable passages of the text of the third book of De natura animalium (NA) by Aelian. (III 2. 60.20-24; 3. 60.27; 18. 67.12-13; 21. 68.1 ; 22. 69.7-10; 23. 69.17-20; 26. 71.23; 26. 71.28-9; 38. 75.29; 42. 77.15; 44. 77.27). In the analysis she attempts to demonstrate, on the one hand, that the language of Aelian is still very poorly known, and how it is necessary to eliminate the conjectures and the alterations which had been arbitrarily made by earlier critics, and to prepare an edition of this work in order to understand well many key passages of his work. On the other hand, she exposes and applies the Textkritisch method, as the koiné literary texts need a rigourous and differenciated treatment that takes into account the period's literary vogue, the evolution and language uses, namely in the phonetic, morphological and syntactic peculiarities of late Greek prose together with the author's usage. Despite all those considerations, Aelian's works has usually been judged and analysed through classical Greek standards. This research is a new contribution to the knowledge of the language of Aelian, of postclassical Greek and of ecdotics for Greek texts of the imperial period.

Keywords: Textual Criticism. The language of De natura animalium by Aelian. The language of Greek late koiné. The textkritisch method. Ecdosis of Aelian's work. Ecdosis of the other texts of the Greek imperial period.

Trato de llevar a cabo un comentario crítico-textual de los principales pasajes del libro tercero de De natura animalium (NA) de Claudio Eliano, 
también llamada Historia animalium, traducciones latinas ambas que reco-

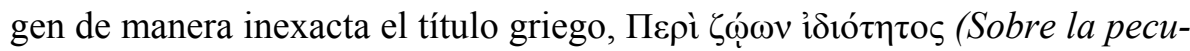
liaridad de los animales). Hay que decir, en primer lugar, que el texto de la obra de Eliano aún no cuenta con una edición moderna basada en los manuscritos más importantes que lo transmiten ${ }^{1}$. Subrayamos, por otro lado, que algunas investigaciones recientes sobre la modalidad de la lengua griega de determinados autores y estudios sistemáticos de las etapas tardías de la misma, han proporcionado un mayor conocimiento de sus características, que incide de manera esencial en un establecimiento correcto del texto. Muchas conjeturas o correcciones en los textos griegos antiguos se deben a una concepción muy estricta de la morfología y de la sintaxis; visión que puede provenir de la rigidez de los Manuales, que están elaborados sobre los textos de ediciones muy antiguas, que no han tenido en cuenta ni siquiera los principales códices que los transmiten y están plagadas de enmiendas y conjeturas. En el caso de los autores pertenecientes a la época helenística, es decir, desde el siglo IV a.C. hasta la que los historiadores califican de época imperial, el asunto es más acuciante, ya que escriben sirviéndose de las normas de la literatura helenística y de la lengua koiné, literaria y popular, y, sin embargo, se sigue juzgando y analizando sus escritos teniendo en cuenta la normativa del griego clásico. Resultan muy necesarias auténticas revisiones de los resultados que se consideraron doctrina admitida para enjuiciar la modalidad de lengua de los textos de época postclásica. Un ejemplo claro es la investigación de Schmid, su obra ya clásica, sobre la lengua de Luciano, Eliano, Elio Arístides y otros autores griegos pertenecientes al movimiento de la Segunda Sofística -entre los siglo II y III d. C. Ese estudio que ha marcado las pautas de lo que se considera ático y propio del estilo de estos autores de corriente aticista, se basó, por un lado, en muy antiguas ediciones, y, por otro, ha tomado como patrón de esa corriente del s. II y siguientes, el ático purista. A partir de esta actuación se extendió una doctrina que se separa mucho de la koiné literaria de la que se sirven de la época. Lo he comprobado en Plutarco y Luciano ${ }^{2}$, en cuyos escritos muchas de sus correcciones y enmiendas se han hecho con el parámetro propuesto por Schmid. En el presen-

\footnotetext{
1 Un equipo de investigación de la Universidad de Oviedo, que dirijo hace y unos años (desde 1999), tiende a ese objetivo, a realizar una edición crítica de la obra $N A$. Queremos expresar nuestro agradecimiento a la DGICYT (PB98-1569).

2 Véanse mis ediciones y artículos sobre estos autores en Nota biliográfica.
}

EMERITA (EM) LXXV 2, julio-diciembre 2007 pp. 199-224 ISSN 0013-6662 
te trabajo, parto de la transmisión manuscrita de $N A$ y de los conocimientos que actualmente se tienen de la lengua griega tardía de un autor perteneciente a los siglos II-III d. C., dentro de la corriente aticista de la Segunda Sofística, intentando poner de manifiesto los errores debidos al enconsertamiento de los textos a las normas gramaticales del ático y ofrecer unas líneas metodológicas de actuación.

La última edición de $N A$ (Hercher 1864) ${ }^{3}$ no presenta un estudio ni descripción de los códices. El breve aparato crítico de la edición, presentado al comienzo, no da información cierta y crea confusión, ya que no indica en ningún caso a qué manuscritos y ediciones anteriores pertenecen las lecturas variantes que ofrece. Se puede considerar de mínima utilidad. El editor afirma, ciertamente, que para establecer el texto sigue el manuscrito $\mathrm{V}$, pero cuando se compara el texto de este códice con el texto editado, no coincide con muchísima frecuencia. Hace correcciones o bien acepta numerosas conjeturas de otros filólogos y él mismo introduce otras muchas; muestra una actitud menos respetuosa con la transmisión manuscrita que en su primera edición (1858). Es considerada, sin embargo, la edición canónica para todo tipo de estudio. Las ediciones anteriores, muy antiguas, siguen siendo útiles para conocer, en muchos casos, el origen de las lecturas de Hercher.

Toda investigación sobre esta obra debe partir del estudio de principios del siglo veinte del italiano De Stefani ${ }^{4}$, sobre la transmisión del texto de $N A$, en el que describe, por familias, diecinueve códices, que van del s. XII al s. XVI. Analiza la relación que hay entre ellos y presenta un stemma codicum.

Después de los estudios que se han hecho, son seis los manuscritos más importantes, AFHLPV. Desde que nos constituimos como equipo, quedaron repartidos los códices entre los investigadores, para llevar a cabo la cola-

3 Sobre las ediciones de la obra, véase Nota bibliográfica.

4 De Stefani (1902) 175-222. En orden alfabético: A = Monacens. August. 564 (s. XIVXV); B = Berolinens. Phillipps. 1522 (s. XVI); C = Parisiens. 1695 (s. XVI); D = Vatic. Palat. 65 (s. XVI); $\mathbf{E}=$ Parisiens. 1694 (s. XVI); F = Laur. 86, 8 (s. XV; G = Barberin. II 92 (s. XVI); $\mathbf{H}=$ Vatic. Palat. 260 (s. XIV); L = Laur. 86, 7 (final del s. XII); M = Monacens. 80 (s. XVI); $\mathbf{N}=$ Neapolit. III D 8 (s. XV); $\mathbf{O}=$ Neapolit. III D 9 (s. XV); $\mathbf{P}=$ Parisiens. 1756 (s. XIV); $\mathbf{Q}=$ Vatic. Palat. 267 (s. XV); $\mathbf{R}=$ Marcian. 518 (s. XV); $\mathbf{S}=$ Vindobonens. med. 7 (s. $\mathrm{XV}$ ); $\mathbf{U}=$ Upsaliens. 27 (s. XV-XVI); $\mathbf{V}=$ Parisiens. suppl. 352, actualmente Vaticanus Graec. 997 (s. XIII); W = Vindobonens. med. 51 (s. XIV). 
ción $^{5}$. Son todos recentiores, menos el ms. antiguo L que es de finales del s. XII. Todos proceden de un arquetipo medieval $(\alpha)$ del que derivan dos ramas de la tradición: una, representada por el ms. V. La otra $(\beta)$ está formada por los códices LPAHF, de los cuales los mss. L y P son copia cada uno de un descendiente diferente de $\beta$. Es decir la rama $\beta$ se divide en dos, de una ( $\left.\beta^{\prime}\right)$ procede su principal representante que es el ms. L, y de la otra $(\gamma)$ derivan los demás (PAHF); P es copia de $\gamma$; mediante dos códices interpositi $\left(\gamma^{\prime}, \delta\right)$ perdidos deriva A; a su vez, mediante otros dos códices interpositi $(\varepsilon, \zeta)$ perdidos deriva el códice $\mathrm{H}$, y mediante otro códice interpositus $(\eta)$ deriva $\mathrm{F}$, códice que presenta un orden de capítulos muy diferente del de los demás manuscritos. Los códices FH requieren una investigación especial, ya que las relaciones entre ambos códices no están estudiadas, ni el orden del material zoológico en el ms. F.

Las interrelaciones y parentesco entre los códices quedan mejor definidos después del trabajo sobre los Excerpta, que De Stefani publicó más tarde ${ }^{6}$, en el que presenta un stemma codicum con mayor precisión, acerca de la relación de estos documentos entre sí y con la tradición de los manuscritos. Los Excerpta Constantini de NA dependen del arquetipo de los manuscritos $(\alpha)$; todos proceden de la tradición $\beta$, ya de $\beta^{\prime}\left(\varepsilon^{\mathrm{c}}, \varepsilon^{\mathrm{f}}, \varepsilon^{\mathrm{l}}\right)$, ya de $\gamma^{\prime}\left(\varepsilon^{\mathrm{k}}, \varepsilon^{\mathrm{v}}\right)$, ya de $\eta\left(\varepsilon^{\mathrm{w}}\right)$; menos $\varepsilon^{\mathrm{m}}$ que deriva de un descendiente perdido del ms. V. Fueron editados por Lambros en el Supplementum Aristotelicum ${ }^{7}$.

Son escasamente útiles para el establecimiento del texto, ya que están concebidos como mínimos extractos, con una elaboración personal del epitomador al comienzo y al final de cada extracto ${ }^{8}$. Sin embargo, merecen cierta

5 El ms. A, que sirvió de base a la edición de Gesner (Zurich 1556), fue colacionado por la Dra. V. Muñoz Alonso. El ms. F y el ms. H fueron colacionados por el profesor M. González Suárez y realizó, asimismo, un estudio sobre ambos, investigación que será objeto de una tesis doctoral. El ms. $\mathbf{L}$, que junto con $\mathbf{P}$ son los dos códices más autorizados de la rama $\beta$, fue base de las ediciones de A. Gronov (Londres 1744) y F. Jacobs (Jena 1832), lo colacioné yo misma. El ms. P fue colacionado por el Dr. L. A. Llera Fueyo. El ms. V, único representante de su tradición, del que se sirvieron los editores Jacobs y Hercher, fue colacionado por la Dra. L. Rodríguez-Noriega Guillén. Quiero expresar mi agradecimiento a todos ellos por la disponibilidad de los resultados de las colaciones que han llevado a cabo y que fueron indispensables para el presente trabajo.

6 De Stefani, “Gli Excerpta”, 1904, pp. 145-180.

7 Cf. Lambros 1885.

8 Cf. Canfora 2002, pp. 47-48, donde compara el modo de compendiar del epitomador

EMERITA (EM) LXXV 2, julio-diciembre 2007 pp. 199-224 ISSN 0013-6662 
atención.

Después de un análisis detallado y minucioso de las dos ramas de la transmisión, sólo tres manuscritos resultan independientes: LPV; para la fijación del texto además de estos tres, son necesarios el ms. $\mathrm{A}^{9}$ (A, Av), y el ms. $\mathrm{H}$, pertenecientes a la línea de transmisión del manuscrito $\mathrm{P}^{10}$. La colación de los códices llevada a cabo por el equipo investigador, ya mencionado, ha puesto de manifiesto las enormes deficiencias de la edición de Hercher. A partir de las colaciones, se fueron estudiando las variantes que presentan los manuscritos, y se ha comprobado que el resultado del trabajo de De Stefani sobre la relación de los diferentes manuscritos, de su último stemma codicum, es muy válido sin cambios sustanciales ${ }^{11}$. Una vez establecido el stem$m a$ por el método de las faltas comunes y se ha llegado al arquetipo del que derivan las ramas de la tradición, la reconstrucción del texto de ese antecesor común medieval debería deducirse casi automáticamente ${ }^{12}$, reconstrucción que no debe confundirse nunca con la redacción original del autor. Pero no es así, el árbol genealógico es un apoyo importante, decía mi querido maestro Lasso de la Vega, para conocer mejor la historia de una tradición; pero sólo cuando la historia de las lecciones consideradas por sí mismas se recubre con la historia del texto figurado en el stemma, sólo entonces nos parece que alcanzamos a captar la realidad de las cosas: delineando la historia de cada elemento crítico, viendo cómo se ha introducido una variante y cómo dicha introducción ocasiona nuevos cambios y alteraciones ${ }^{13}$.

El método estemático es el proceder científico, pero no se puede aplicar

de los Excerpta Constantiniana, siendo escasamente útiles y el de Focio en su Biblioteca.

9 El manuscrito A sufrió la pérdida de algunos folios y fueron suplidos por una segunda mano del s. XV, mediante copia de un descendiente de V (de ahí A, primera mano; Av, segunda mano). Av, afín a V, transmite las partes siguientes: índice del libro I, proemio y I 138, 45-53, 58-60; II 1-6, 9-11, 13-26, 37-47; III índice y cc. 1-14; V 34-41; VI 9-15; XVII 3841. El ms. V, por tanto, en la mayor parte de la obra es único representante de su tradición.

10 Estudiado el ms. F y su relación con $\mathrm{H}$, dadas las alteraciones que presenta del texto, tanto en su contenido como en el orden, no es útil en la edición, a no ser en pasajes muy concretos.

11 Véase, De Stefani, “Gli Excerpta”, 1904, p. 169.

12 La regla "de hierro" según el método de Lachmann, es bien conocida: la concordancia de dos tradiciones contra una tercera debe dar automáticamente la lección del antepasado común.

Véase, Lasso de la Vega 1984, p. 147.

EMERITA (EM) LXXV 2, julio-diciembre 2007 pp. 199-224 ISSN 0013-6662 
como norma fija e inamovible. La investigación debe tomar como base no la calidad de cada uno de los manuscritos, o de cada rama de manuscritos, sino el valor intrínseco de las variantes. Esta es la situación que se encuentra, con frecuencia, en el texto de Eliano. Las dos ramas que transmiten la obra (V $\beta$ ) son necesarias en la constitución del texto y no hay una prevalencia clara de una sobre la otra. Se deben valorar las lecturas variantes, se ha de examinar caso por caso, y escoger la variante buena, que no significa auténtica, sino simplemente la más atendible de las examinadas. Siempre con la convicción de que la lectura variante que prefiramos no es la original, sino la lectura de aquella rama de la tradición, o agrupación de códices, que según nuestra experiencia contiene menos número de pasajes corruptos ${ }^{14}$. Es mejor hablar solamente de grados diferentes de probabilidad. La situación es con frecuencia ardua.

Las dos ramas $(\mathrm{V} \beta)$ son, como se ha dicho, necesarias para el establecimiento del texto. El método y valoración más fiable de las variantes para restablecer el arquetipo, dada la relación entre los códices, deben atenerse a las pautas siguientes: $1^{\circ} \mathrm{El}$ principio general es el de respeto al textus receptus sin caer en el fetichismo: cuando los códices concuerdan se tiende a mantener esa lectura y a suprimir las correcciones, enmiendas o conjeturas que existan, a no ser que haya razones muy justificadas para acturar de otro modo. $2^{\circ} \mathrm{Si}$ no concuerdan los manuscritos $\mathrm{VA}^{\mathrm{v}}$, y concuerdan los de $\beta$, es más fiable, en principio, la lectura de $\beta$; y, viceversa. $3^{\circ}$ Cuando los mss. difieren, debería darse la preferencia de la variante en el orden siguiente: a) aquella en la que coinciden los manuscritos VLP establece con seguridad la del arquetipo. b) la lectura en la que concuerdan los manuscritos VL, o bien VP, tiene un valor muy notable; es con mucha frecuencia segura, pero no siempre, lo sería más si concuerdan también los códices $\mathrm{AH}$ con uno de ambos grupos. $4^{\circ} \mathrm{Si}$ el ms. V testimonia una lectura variante y los mss. LPAH ( $\beta$ ) otra, se debe estudiar cuál es la preferible. La concordancia de todos los códices de $\beta$, por pertenecer a la misma tradición, no hace la lectura más fiable, pero tampoco menos que la de $\mathrm{V}$, ya que este códice presenta omisiones y errores propios. Dada la transmisión manuscrita de la obra, en la que, en su mayor parte, una rama está documentada sólo por un códice (V), debe estudiarse con gran cuidado cada pasaje que presenta una lectura variante diversa en

14 Véase, Waszink 1975, pp. 7-34 (22-23). 
cada rama. Esta situación se plantea con gran frecuencia en la obra y es difícil decidir cuál es la variante que correspondería al arquetipo. Cada rama de la tradición presenta una lección y no hay argumentos seguros para realizar la preferencia. En estos pasajes, el camino sería acudir a la autoridad del manuscrito, es decir, aquel que da el mayor número de lecturas buenas en pasajes en los que hay argumentos racionales para adoptar una decisión. Éste es el que tiene más posibilidades que los otros de dar la lectura más atendible en los demás pasajes en los que no existen tales argumentos. Esto que en teoría puede resultar convincente, no lo es tanto en la práctica, ante la demostración documental de esta obra. $5^{\circ}$ En ocasiones, no concuerdan los códices de $\beta$, debido al error de uno de sus manuscritos, pero transmiten la lectura buena los demás testimonios de esa rama, frente a la lección errónea de V (con más frecuencia en la parte de la obra en que es único representante de esa rama). $6^{\circ} \mathrm{Si}$ difieren mucho, de tal manera que los mss. de $\mathrm{V}$ no concuerdan, ni, a su vez, los que constituyen la rama $\beta$, y los editores han conjeturado a su gusto, deben hacerse prevalecer los criterios internos del texto, el estilo y la lengua del escritor, y las características de la koiné de la época, para tratar de restituir el texto del arquetipo. Se está observando que los usos de la lengua del autor y las características de la koiné de la época, hacen prevalecer, en algunas ocasiones, la lectura de un códice solo, frente a variantes diversas de los otros o, incluso, al acuerdo de algunos de los otros.

Este procedimiento seguido, en un número grande de lecturas, es altamente eficaz para hallar la lección más atendible del arquetipo.

Pasemos al comentario de los pasajes del libro tercero que considero más ilustrativos de la variada problemática que presenta la tradición manuscrita de la obra ${ }^{15}$. Este libro, como los diecisiete que componen la obra, ofrece una miscelánea de curiosidades zoológicas. Las costumbres de los animales son descritas, en algunos casos, atendiendo a los conocimientos de la moderna zoología, en otras ocasiones se narran con mucha fantasía y con una ingenuidad grande, que separan abiertamente al autor de una mentalidad científica y lo unen a los paradoxógrafos de su época. El objetivo principal del escritor es mostrar, según la doctrina estoica, la sabiduría de la Naturaleza,

15 En las citas del texto griego, sigo la edición de R. Hercher (1864), indicando libro, capítulo, página y línea.

EMERITA (EM) LXXV 2, julio-diciembre 2007 pp. 199-224 ISSN 0013-6662 
confrontando el comportamiento de los animales con el de los seres humanos $\mathrm{y}$ tratando de poner de manifiesto todo aquello en lo que los animales aventajan a los humanos.

III 2.60.20-24. En el argumento del capítulo se comparan las cualidades de los caballos libios y los persas. El pasaje es un buen ejemplo de la dificultad

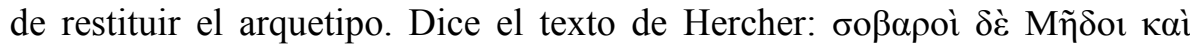

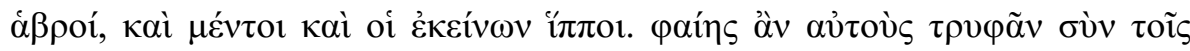

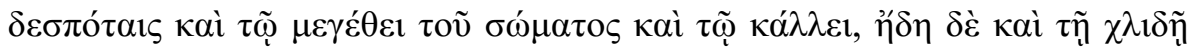

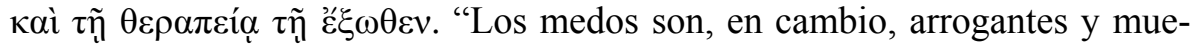
lles, como también sus caballos. Dirías que ellos con sus dueños se enorgullecen del tamaño de su cuerpo y de su belleza, y también de sus galas y del cuidado exterior".

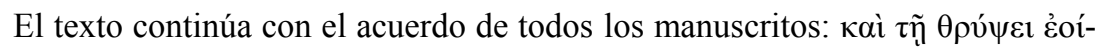

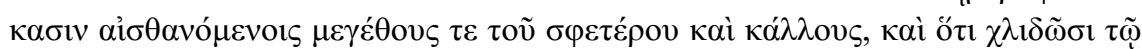

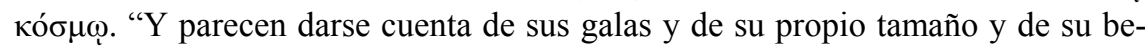
lleza, y que se envanecen con su adorno".

La primera cuestión que se plantea es que este último pasaje sea una adición, puede parecer originariamente una glosa y que se haya introducido en el texto. El consenso de los códices, sin embargo, permite restituir el arquetipo con el texto completo. En el arquetipo del que derivan las dos ramas ya se encontraba, sin duda, y tiene un significado muy inteligible y expresivo. Los editores, Gesner, Jacobs, Hercher (1858) establecen el texto completo; Hercher lo mantiene, pero

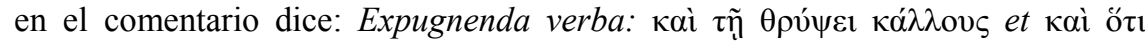

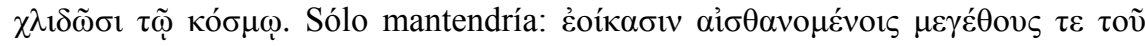

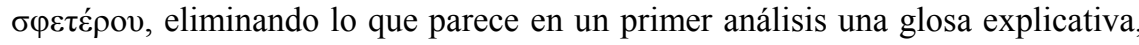
debido a la insistencia y repetición de los vocablos (v. Hercher, Praefatio, p. III). Sin embargo, las sucesivas traducciones latinas, que acompañan las antiguas ediciones mantienen en su versión el texto completo. En la última edición (1864), Hercher, siguiendo su comentario hecho en la primera edición, lo elimina. Se repiten, sin duda, las raíces de algunos vocablos o incluso las mismas palabras:

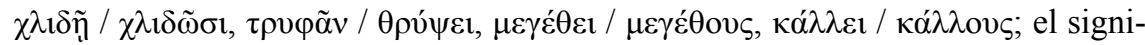

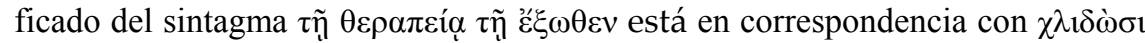

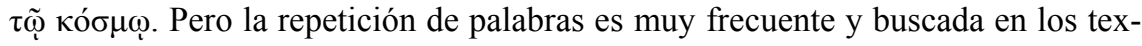
tos en koiné. Se pueden citar ejemplos de otros autores de la misma época y ya se encuentra en la prosa de Tucídides y en la época helenística ${ }^{16}$. Es un giro estilís

16 Véase, entre otros, Th. I,105,1-2; sobre las repeticiones y anáforas, Foucault 1972, p. 271 ss.; Giangrande 1991, pp. 65, 87; García Valdés 1995, Is. et Os. 355C-D, 379C, comenta- 
tico con una gran fuerza expresiva. En el presente pasaje: una vez comienza el párrafo con la afirmación de dos cualidades de los hombres medos, dice que también las tienen sus caballos; esto lleva al escritor a la imagen del caballo con su dueño como jinete, formando una unidad inseparable; en esa unión se confunde la sensación mutua de las cualidades; caballo y dueño se enorgullecen del tamaño de su cuerpo y de su belleza, de sus galas y del cuidado exterior. A continuación, son los caballos, ellos solos, los que parecen captar, sentir esas cualidades y adorno. Hay una gradación buscada, que, in crescendo, aumenta, multiplica, al final, la ponderación de los caballos. Logra una mayor expresividad llegando a la hipérbole en la descripción de los caballos persas. La repetición es artísticamente buscada, su uso es muy frecuente en la la koiné, y tiene una función singnificativa y estética en el texto.

III 3.60.24-28. En el mismo contexto que el anterior, sobre los caballos de Libia y de Persia, el autor se refiere a los perros, y de manera particular, a las cualidades de la perra cretense (ligera, saltadora y adiestrada para andar por las montañas), y los cretenses, al igual que los persas, manifiestan también estar dotados de las mismas cualidades que ella. El texto es el siguiente: $\tau \alpha \tilde{v}-$

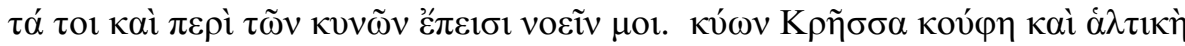

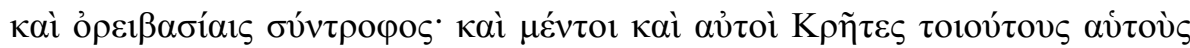
$\pi \alpha \rho \alpha \delta \varepsilon 1 \kappa v v ́ \alpha \sigma 1, \kappa \alpha \grave{~ \alpha ̆ \delta \varepsilon ı ~}$

El editor establece $\pi \alpha \rho \alpha \delta \varepsilon ı \kappa v v ́ \alpha \sigma l$. Los mss. transmiten: $\pi \alpha \rho \alpha \delta \varepsilon i ́ \kappa v v \sigma \iota \mathrm{VH}$, $\pi \varepsilon \rho \iota \delta \varepsilon i ́ k v v \sigma \iota$ LPAv. El verbo compuesto con el preverbio $\pi \varepsilon \rho 1-$ aparece sólo una

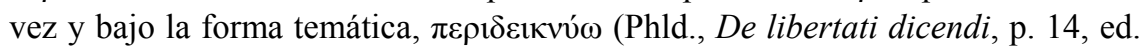
Olivieri); en cambio, el verbo con el preverbio $\pi \alpha \rho \alpha$-, bajo formas atemáticas y temáticas, es frecuente a partir de Polibio (véase, s. v. Stephanus y LiddellScott). Transmiten correctamente el preverbio $\pi \alpha \rho \alpha ́$ los mss. VH. La confusión de estos dos preverbios es muy fecuente en la transmisión textual. Así determinados manuscritos de las dos ramas (Av y LP) lo han alterado, muy probablemente,

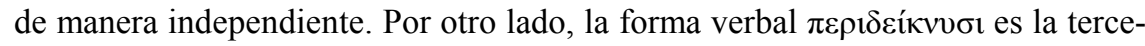
ra persona de singular; sin embargo, se observa, de manera evidente, por su suje-

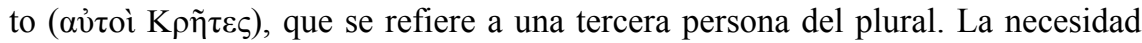
de la tercera persona de plural la señala también Hercher quien la modificó estableciendo $\pi \alpha \rho \alpha \delta \varepsilon \varepsilon \kappa v v ́ \alpha \sigma t$ pro $\pi \alpha \rho \alpha \delta \varepsilon i ́ \kappa v v \sigma l$, a partir del morfema desinencial de tercera persona del plural - $v \tau \imath$ (con la vocalización de la $v$ en $\alpha$ y la asibilación de $-\tau \iota$ en $-\sigma \iota)$. La forma verbal $\pi \alpha \rho \alpha \delta \varepsilon i ́ \kappa v v \sigma ı$ tercera persona de singular, si sufre

rio p. 322; Ev. Mc. 8,27. En textos poéticos helenísticos, véase, Giangrande 1989, pp. 3-44 (p. 31 , sobre la iteratio).

EMERITA (EM) LXXV 2, julio-diciembre 2007 pp. 199-224 ISSN 0013-6662 
una mínima modificación del acento, $\pi \alpha \rho \alpha \delta \varepsilon ı \kappa v \tilde{\sigma} \sigma$, es la tercera persona del plural, explicable por la perdida de la $v$ y el alargamiento compensatorio de la vocal anterior, por lo que toma el acento circunflejo. De manera similar, debió experi-

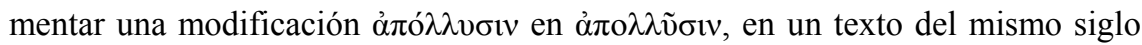
(Luc., Par. 6. 18-19) ${ }^{17}$. La transmisión de todos los códices, si se prescinde del preverbio, es $\delta \varepsilon i ́ \kappa v v \sigma t$ y, por tanto, como tercera del plural, debe modificarse en $\pi \alpha \rho \alpha \delta \varepsilon ı \kappa v v \tilde{\sigma l}$. De un modo general, se ha tenido tendencia a sustituir la flexión

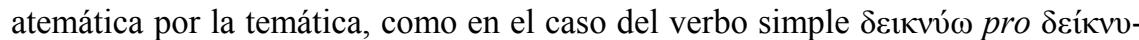

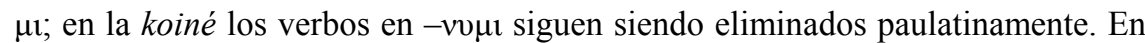
el presente pasaje y con gran frecuencia, continúa empleada la forma atemática del verbo.

III 18.67.11-18. El capítulo trata del "pez globo" y del carácter dañino de su pesca, ya que llega a provocar la muerte del que lo come. Pero a su vez, el

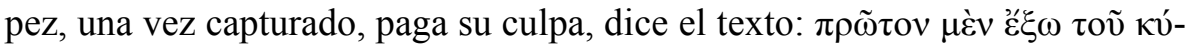

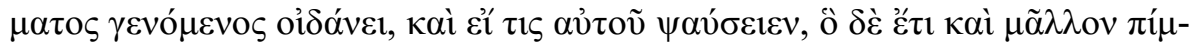

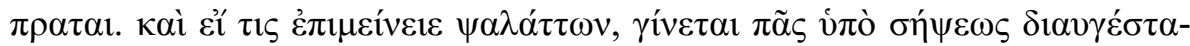

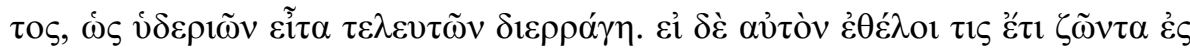

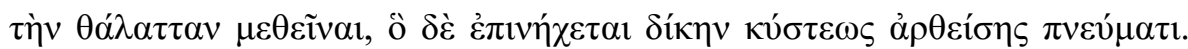

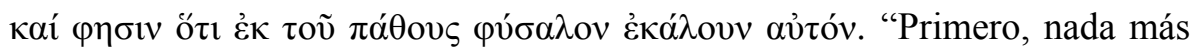
que esté fuera del agua, se hincha, y si alguien lo toca quema hinchando más y más; y si alguien sigue manipulándolo, se corrompe todo llegando a estar muy translúcido, como un hombre hidrópico; y luego revienta. Y si se le quiere dejar libre echándolo al mar aún vivo, éste nada sobre la superficie, como una vejiga llena de aire. Y se afirma que a causa de esta propiedad lo llamaban pez "globo".

El pasaje es interesante, por ofrecer ejemplos de la libertad con la que los editores alteran el texto transmitido por los manuscritos y, a la vez, para observar el empleo de los modos en los enunciados condicionales, ya que hay tres en el párrafo, que iremos analizando. Este tipo de actuación es muy frecuente, lo vamos a comparar con otros pasajes, y se debe, principalmente, a no tener en cuenta el uso de los modos en la koiné. Hercher altera, sin necesidad, las formas verbales de la prótasis de los dos primeros enunciados, intentando uniformar el modo de

17 Cf., García Valdés 2001, p. 229. Decía Schmid en nota a pie de página: velim minima mutatione (ed. 1779) $\alpha \dot{\pi} \mathrm{o} \lambda \lambda \tilde{v} \sigma$ legere; forma que está empleada así por Heródoto (IV 69) y por Platón (Leg. 706). Cf. Veitch 1967, s.v. p. 484; otros editores antiguos intentaron corregirla ante la necesidad de una tercera personal de plural, y propusieron $\alpha \dot{\alpha} \mathrm{\alpha} \lambda \lambda v ́ \alpha \sigma$. 


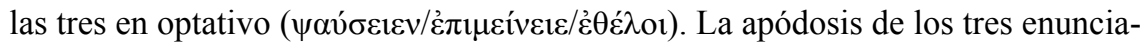
dos tiene el predicado verbal en presente de indicativo.

Veamos el primer enunciado condicional, los manuscritos testimonian en la

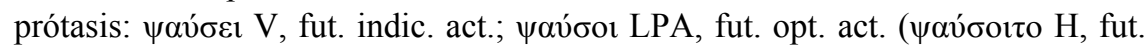
opt. med.). Los editores Gesner y Hercher no se atienen a la tradición manuscrita, Gesner establece $\psi \alpha v$ oṇ, aor. de subj., y Hercher en su primera edición, siguiendo la enmienda de Schneider, establece $\psi \alpha v$ $\sigma \alpha$, aor. de opt. act.; en su segunda

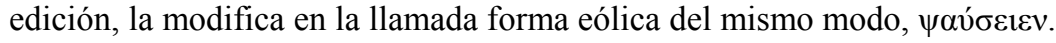

Los códices presentan, como se observa, divergencia en el modo del verbo de la prótasis. Se trata del uso de $\varepsilon \hat{\imath}+$ opt. fut. ( $\varepsilon \grave{i} \tau 1 \zeta \psi \alpha v ́ \sigma o \imath)$, o bien, $\varepsilon \hat{\imath}+$ ind. fut. ( $\varepsilon \grave{\imath}$

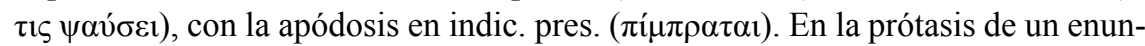
ciado condicional, las dos construcciones son posibles en la koiné. La cuestión es explicar la divergencia y si es posible restituir la forma verbal del arquetipo.

(Son significativos otros ejemplos que presentan prótasis en fut. ind. y apódosis en presente ind., o bien, dos prótasis en opt. de aor. coordinadas con otra prótasis en fut. de ind. y apódosis fut. de indic.: XVI 19.398.15-16. Se refiere a las liebres marinas por sus pelos en forma de púas: "si uno las toca, recibe un pinchazo".

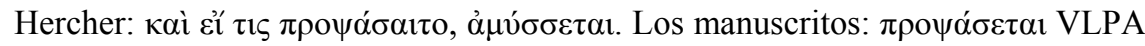

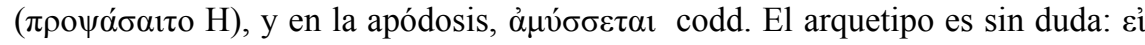
$\pi \rho о \psi \alpha ́ \sigma \varepsilon \tau \alpha 1, \grave{\alpha} \mu v ́ \sigma \sigma \varepsilon \tau \alpha 1$. Hercher corrige de manera innecesaria el texto, modificando el fut. ind. en aor. opt.

Veamos, también, II 29.48.19-21. El autor se está refiriendo a la mosca: aunque de los animales es la criatura más intrépida, si cae al agua no puede correr ni

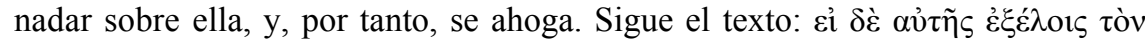

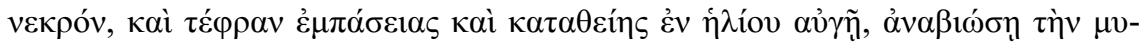
iav. "Pero si sacas el cadáver y esparces ceniza sobre él y lo expones a los rayos del sol, resucitarás a la mosca". Hay tres verbos coordinados en la prótasis, los

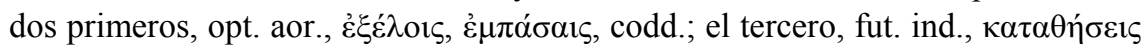

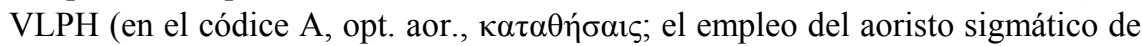
$\tau i ́ \theta \eta \mu$ es propio de la koiné muy tardía, siglo tercero en adelante, cf. Chantraine $\S 181$; el escriba del ms. A corrigió el fut. en aor., acudiendo a la forma de aor., usada ya en su tiempo, intentando uniformar el modo optativo en las tres próta-

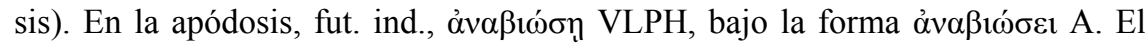
arquetipo, según la transmisión manuscrita, presenta, en la prótasis, tres oracio-

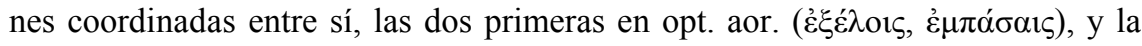
tercera en ind. fut. ( $\kappa \alpha \tau \alpha \theta \dot{\sigma} \sigma \varepsilon 1 \zeta)$; en la apódosis, fut. ind. No se debe alterar el texto como ha hecho Hercher, de modo innecesario, estableciendo erróneamente

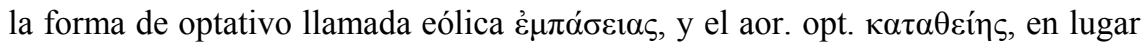

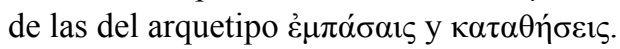

EMERITA (EM) LXXV 2, julio-diciembre 2007 pp. 199-224 ISSN 0013-6662 
Otro ejemplo de Eliano, VIII 26.216.9, en el que se encuentran coordinados

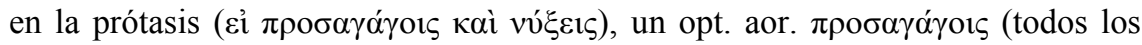

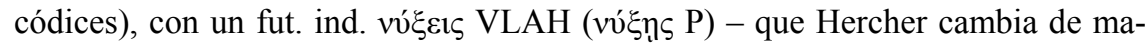

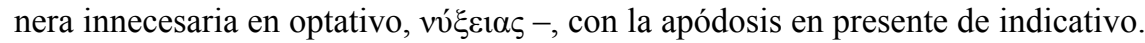
Se observa, en consecuencia, que el autor emplea, en la prótasis, las dos construcciones, $\varepsilon \grave{i}+$ opt. aor., o bien, $\varepsilon \grave{i}+$ ind. fut., coordinadas entre sí, como se encuentra en la koiné literaria, en la que los autores se expresan entre una correcta sintaxis ática y vulgarismos sintácticos; tales fluctuaciones son muy comunes en los escritores de la koiné tardía ${ }^{18}$ )

Estos ejemplos, en los que están coordinados, en la prótasis, el opt. aor. con indic. fut., muestran la dificultad de decidir, para restituir el arquetipo, en el pasa-

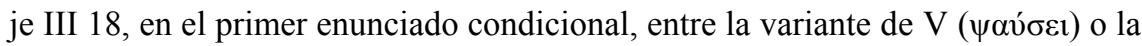

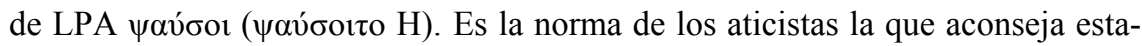

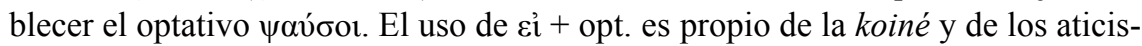
tas, llegando a emplearse el optativo, tras su casi desaparición en la época helenística ${ }^{19}$, con una mayor frecuencia desde el s. I a.C., y aún mayor en el s. II d.C., al intentar imitar a los autores clásicos. El deseo de emplear la construcción propia del ático, lleva al uso hipercorrecto del modo optativo; éste llega a usarse como sustituto del indicativo o del subjuntivo, se encuentra el empleo alternativo de żóv + subj. o, bien, ż̀ + opt., como construcciones sin diferencias de significado. A partir de ahí, se encuentra usada la partícula ớv de modo incorrecto, su presencia o ausencia no se atiene a las normas del griego clásico. Se encuentra ơv usada con indicativo (Blass-Debrunner \$382,4; Mayser II, I, p. 284 ss., y también I, I, 128 c). O bien se emplea el subjuntivo prospectivo sin ớv (véase, III

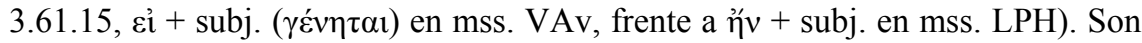
usos propios de la koiné vulgar que se introducen en la prosa literaria de la mis-

18 Cf. Giangrande 1984, Anton. Liber., XX 2-3, donde están coordinadas dos prótasis:

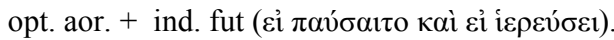

19 No cabe duda de que la evolución del vocalismo, en particular de los diptongos $\varepsilon \mathbf{l}, \eta n$, ol (cf. Lejeune 1987, pp. 236, 241), ocasionó la confusión de los morfemas: en la voz activa, de la tercera pers. sing. del fut. indic., del aor. subj. y del aor. opt. (también del pres. ind. y del pres. subj.); en la voz media, la segunda pers. sing. del fut. ind. y del aor. subj.; y en la voz pasiva, la confusión de la segunda pers. del pres. ind. con la del pres. subj.). Esta confusión fonética, va conllevando la desaparición del morfema que marcaba la oposición en el empleo de los modos, entre subjuntivo y optativo, oposición que marcaba una diferencia de significado. Los manuscritos manifiestan este fenomeno en las diferentes variantes que transmiten. Estos factores fonéticos, otros sintácticos y de otro tipo, contribuyeron a la desaparición del optativo, de manera total en el griego moderno, es sustituido por el subjuntivo en oraciones independientes y en todo tipo de subordinación. Véase, M. García Teijeiro 1983, pp. 247-277; R. Adrados 1992, pp. 531-542. 
ma época.

Se observa precisamente este fenómeno en el segundo enunciado condicional del pasaje que venimos comentando (III 18), $\varepsilon \dot{i}+$ subj. aor. sin partícula en la

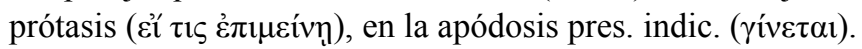

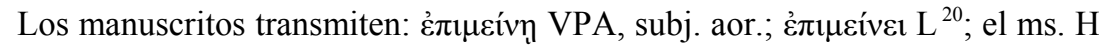
atestigua $\dot{\pi} \pi \mu \varepsilon_{i} v_{n}$, con cambio del preverbio, alteración muy frecuente en la transmisión manuscrita, entre غ̇ंí y íđó; en la forma simple del verbo, H concuer-

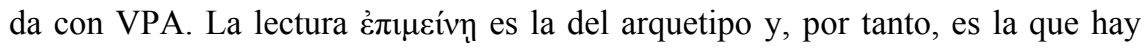
que establecer, como ha hecho Gesner. Se emplea en la koiné tardía las construc-

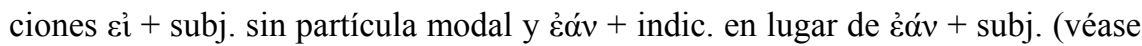
Blass-Debrunner \$372) ${ }^{21}$. Los escritores de la koiné literaria que tratan de imitar el ático emplean la partícula ớv "incorrectamente", es a modo de un "disparate" sintáctico, que no debe ser enmendado. Jacobs, siguiendo a Schneider, establece

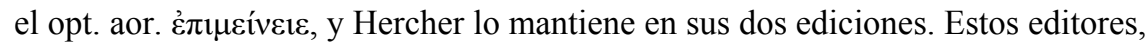
considerando esa construcción un error (cf. el comentario de Jacobs, p. 111), modifican, sin necesidad, la tradición manuscrita. Otro pasaje del mismo libro, III 41.76.24-27, presenta una situación similar, si se observa el reparto de variantes. Se refiere a las propiedades del cuerno del unicornio, con el que se fabrican vasi-

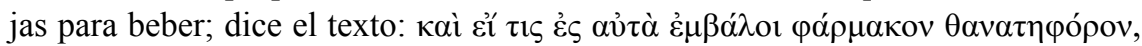

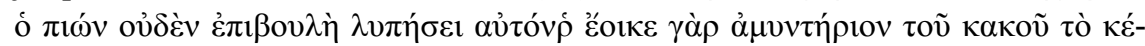

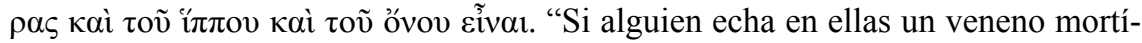
fero, el que lo bebe no recibirá daño alguno de la conjura, pues parece que el cuerno tanto del caballo como del asno es un antídoto contra el veneno." Los

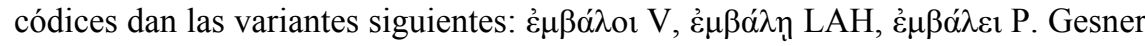
establece, siguiendo el ms. A, $\dot{\varepsilon} \mu \beta \alpha ́ \lambda \eta ̣$, en esta variante vuelve a encontrarse el empleo del subjuntivo prospectivo sin partícula modal. Jacobs y Hercher establecen $\dot{\varepsilon} \mu \beta a ́ \lambda o$, es la lectura que se debe restituir.

20 Forma en la que se da la confusión en el vocalismo entre $\varepsilon ı$ y $\eta$ debido a la evolución de estos dos diptongos, con monoptongación del diptongo $\varepsilon$, y con pérdida del segundo elemento, la 1 , del diptongo largo ṇ, coincidiendo ambos en la pronunciación en 1 , por el fenómeno de iotacismo.

${ }^{21}$ Ya en Homero todas las oraciones subordinadas de subjuntivo (excepto las de íva, las de temor y las comparativas), llevan ya partícula ya no. La partícula modal de la prótasis, en juicios de carácter general, falta a veces en la poesía arcaica, en la tragedia y raramente en prosa. Es el ático el que generaliza ớv en el subjuntivo de casi todas las subordinadas; la construcción de la oración condicional $\varepsilon^{i} \alpha^{\prime} v+$ subj. ( $\varepsilon \dot{\alpha} v+$ subj. en la época postclásica) es la norma para la prótasis de la condición eventual referida al futuro, o bien, de la condición general de presente-futuro. En el griego helenístico, en cambio, cada vez tiene menos importancia la presencia o ausencia de ớv (confundida con çóv). Véase, A. Díaz Tejera 1989, pp. $73-$ 92; R. Adrados 1992, pp. 528-530; Crespo 2003, pp. 437-443 (438).

EMERITA (EM) LXXV 2, julio-diciembre 2007 pp. 199-224 


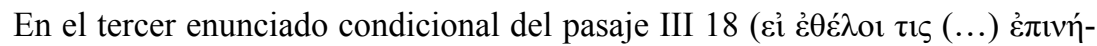
$\chi \varepsilon \tau \alpha \imath)$, se encuentra $\varepsilon \grave{\imath}+$ opt. de pres., con pres. de indic. en la apódosis. Se observa el empleo, como en otros autores aticistas, de $\varepsilon \dot{\imath}+$ opt., en dependencia de apódosis cuyo verbo no se refiere al pasado. En la prótasis, los manuscritos trans-

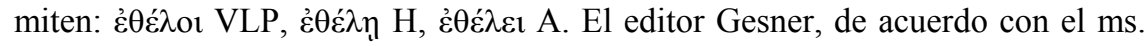
A, que sigue en su edición, establece $\dot{\varepsilon} \theta \varepsilon \dot{\lambda} \lambda \varepsilon$. Hercher mantiene la lectura de los mss. VLP غ̇⿴囗́̉ rresponde al arquetipo.

Otros dos ejemplos ilustrativos, III 24.70.13-15: Se está refiriendo al material con el que las golondrinas construyen el nido. El modo de actuar de estas aves es diverso según tengan a disposición barro o les falte y tengan que elaborarlo. Dice

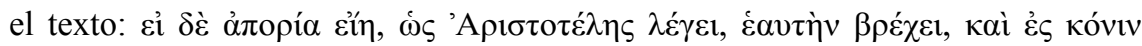

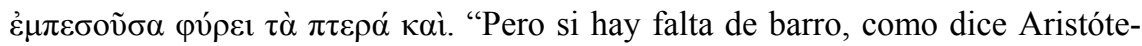
les, se mete en el agua y revolcándose luego en el polvo, embadurna sus alas".

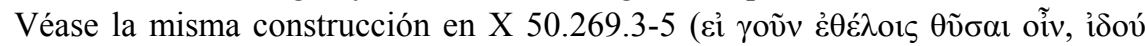

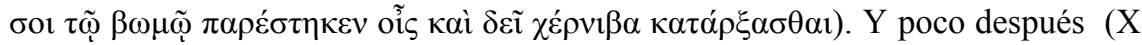

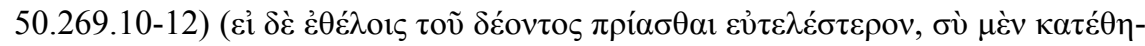

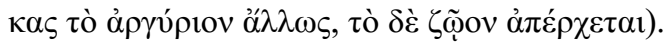

En cuanto al uso de los modos, estos ejemplos se ajustan totalmente al uso propio de los aticistas: está empleado el optativo en la prótasis de oraciones condicionales, con la apódosis en un tiempo no referido al pasado. Se observa además, en el útimo pasaje, dos modificaciones muy llamativas de la tradición manuscrita sin ninguna justificación. En primer lugar, la transmisión unánime de los

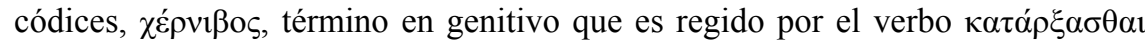
"comenzar la ablución" 222 es la lectura correcta; la modificación de Hercher, $\chi \varepsilon ́ \rho-$ $v ı \beta \alpha$, es injustificable, cuando la transmisión de los manuscritos es concorde. De modo igualmente innecesario, el editor altera el adjetivo transmitido por todos los

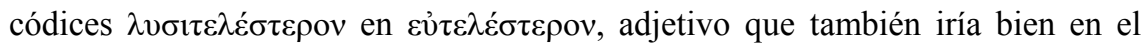
contexto del pasaje, pero que los manuscritos no testimonian. El autor se está refiriendo a la compra del animal para el sacrificio: la diosa Afrodita de Érice vigila que los precios de venta sean justos y que éstos sean los que paga el comprador; es el modo de tener a la diosa propicia; y si no es así, si se trata de sacar

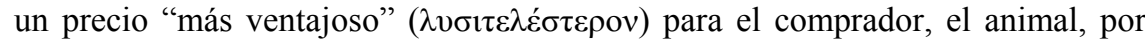
influjo de la diosa, se marcha, y el comprador no puede sacrificarlo. El significa-

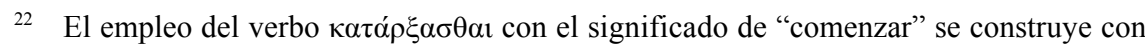
genitivo: E., Ph. 540; Pl., Phdr. 256 d; Plb. 2. 67. 1; Plu., 2. 151C; y también en el sentido religioso, "comenzar la ablución", "comenzar el sacrificio", rige genitivo: cf. E., $P h$. ( $\theta$ v$\mu \alpha \dot{\tau} \omega v)$ 573; IT 56, 1154. D. (icpòv) 21.114. Se encuentra el acusativo en E., Hec. 685, como una variante. Cf. Liddell-Scott, s. v. 
do de "más ventajoso", implica, en el contexto, el significado "más barato", sin necesidad de alterar el adjetivo transmitido por toda la tradición manuscrita.

III 21.68.1-4. El autor refiere cómo una pareja de leones se venga de una osa que mató a sus cachorros en la guarida no vigilada de los leones. Dice el tex-

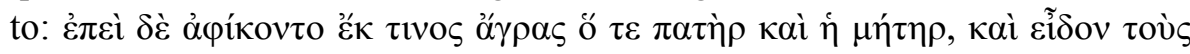

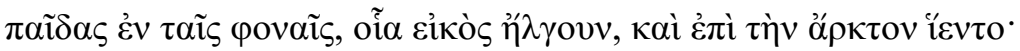

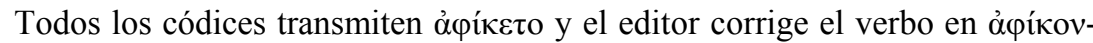

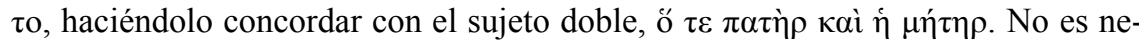
cesaria la corrección. Cuando hay varios sujetos y el verbo está delante colocado, concuerda el verbo con el primero (cf. Blass-Debrunner, §135; p. 74. Adrados, Sintaxis, p. 370 (1)). Del empleo en singular se hace el paso a plural en los verbos que siguen, lo que es correcto en griego. El texto debe establecerse, según el consenso de los códices, como ya lo hicieron los editores Gesner y Jacobs: $\alpha$ $\varphi$ í-

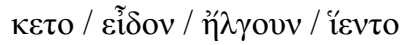

III 22.69.7-10. En el capítulo se describe la lucha del áspid y la mangosta. El

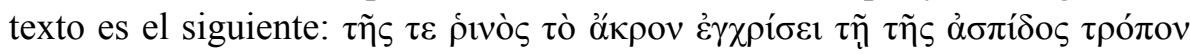

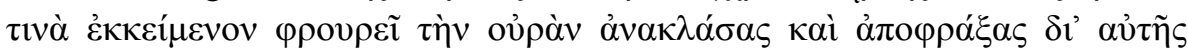
av̉ंó.

Los manuscritos después de ókpov coinciden todos en añadir $\alpha \dot{\alpha} \alpha \lambda \grave{o ̀ v}$ óv

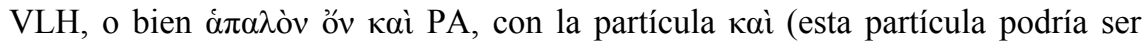
indicio de que $\alpha \dot{\alpha} \alpha \lambda \grave{o} v$ öv es una glosa introducida en el texto y la partícula sería

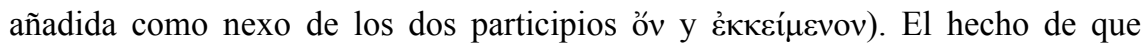
coincidan todos los códices en la adición, $\alpha \pi \alpha \lambda$ òv öv, es un indicio fiable de que estaba en el arquetipo del que proceden todos los manuscritos, aunque esto no garantiza que estuviera en el texto manuscrito del autor; ya que el material que transmite la obra se ha prestado a adiciones, glosas al margen, que pudieron ser

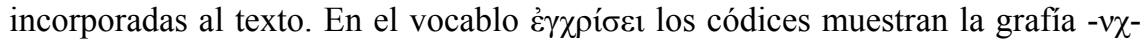
(véase, Mayser §39.2a), y algunos notan de manera errónea por el fenómeno fo-

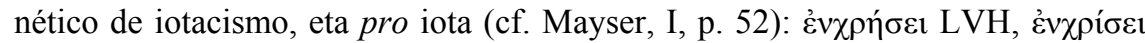

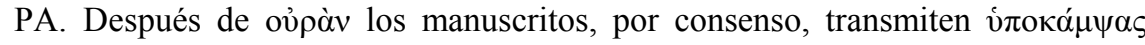

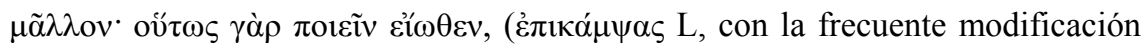
del preverbio, que ya se ha visto). Es el texto que debe ser establecido dada la unanimidad de todos los testimonios manuscritos.

Se observa, en el contexto del pasaje, que los códices dan una descripción más detallada de la escena y la intención del autor es insistir en la costumbre de

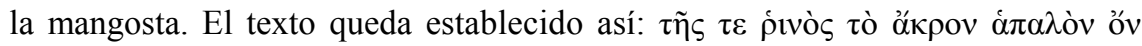

EMERITA (EM) LXXV 2, julio-diciembre 2007 pp. 199-224 ISSN 0013-6662 


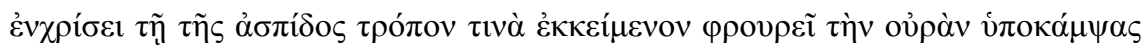

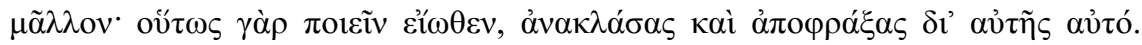
"Protege la punta de su nariz, que es delicada, expuesta de alguna manera a una mordedura del áspid, plegando más su cola; pues así acostumbra a hacer: desviándola hacia arriba y ocultándo la punta por medio de ella".

III 23.69.17-22. Eliano se está refiriendo a las cigüeñas, aves que atienden con amorosa solicitud a sus padres ya viejos y a sus crías, y considera que la ley que les impulsa no es una ley humana sino la causa de su conducta es la Naturaleza. Dice el texto refiriéndose al cuidado hacia las crías: $\dot{\alpha} \lambda \lambda \dot{\alpha} \alpha i \tau^{\prime} \alpha$

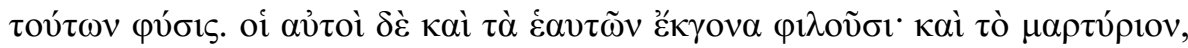

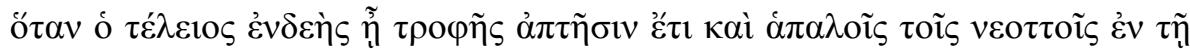

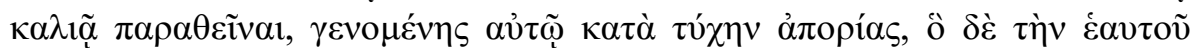

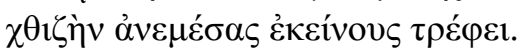

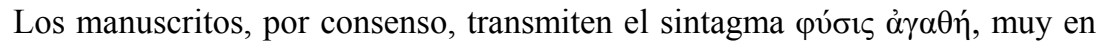
consonancia con el pensamiento de Eliano; la expresión significa "la Naturaleza buena", "la bondad de la Naturaleza", con el adjetivo en uso predicativo. No hay motivo alguno que justifique la supresión de $\alpha \gamma \gamma \alpha \theta \eta$, como hace Hercher en su edición. Los editores anteriores (Gesner, Hercher 1858) y la traducción latina de Gillius (sed sola bonitate naturae ad id impellantur), confirman la presencia del

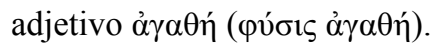

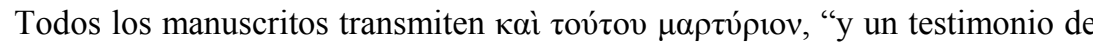
esto". Es un sintagma que constituye una oración nominal pura, en la que el pro-

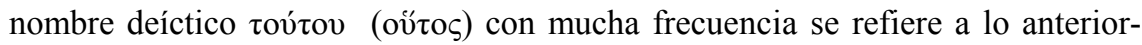
mente dicho en su valor anafórico, pero se usa también para adelantar la referencia de la oración que sigue, que es su empleo en este pasaje. En la koiné el pronombre ő $\delta \varepsilon$ tiende a desaparecer y oứo (véase Myser \$290 (3), cf. Adrados, Sintaxis, p. 318). Hercher, sin ninguna justi-

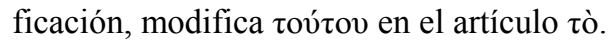

En la oración temporal que comienza por ö $\tau \alpha v$, los códices se dividen en la

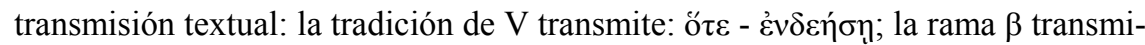

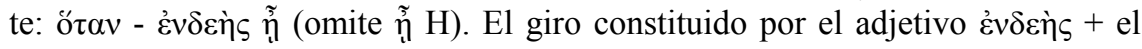
verbo cỉní + infinitivo es un uso frecuente del griego clásico, y también el verbo

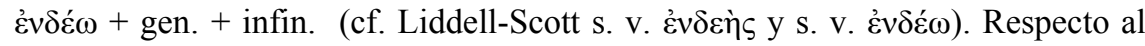
modo del verbo es el subjuntivo en ambas ramas, aunque un corte diferente de la

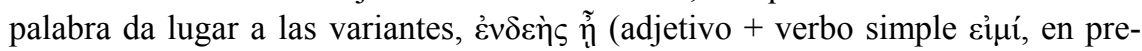

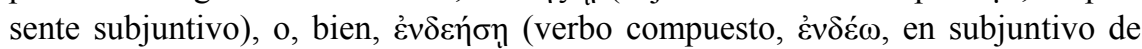
aoristo + infinitivo). El autor intenta ejemplificar el comportamiento de la cigüe-

EMERITA (EM) LXXV 2, julio-diciembre 2007 pp. 199-224 ISSN 0013-6662 
ña adulta con una actuación que se repite respecto al hecho de alimentar a las crías $^{23}$.

El uso en Eliano en las oraciones temporales (en 142 casos, 63,39 \%, el verbo de la oración subordinada está en aor. de subj.; en 69 casos, 30,8\%, está en pres. de subj.), aconseja establecer el aor. subj. Sin embargo, dado que el verbo cì carece de aoristo, ambas construcciones pueden expresar el mismo significado.

La cuestión está en el uso alternativo de ö $\tau \varepsilon+$ subj., ms. V / ö $\tau \alpha v+$ subjuntivo, mss. LPAH. El uso alternativo, en la koiné literaria, en las oraciones temporales (de manera similar a las condicionales), de ö $\tau \varepsilon+$ opt. / ö $\tau \alpha v+$ subj., lleva al empleo de una u otra construcción, con ausencia o presencia de partícula de manera incoherente y sin obedecer a unas normas fijas, y al uso por hipercorrección de la partícula ớv en las oraciones subordinadas.

En este mismo libro, véanse dos ejemplos: de construcción de ö $\varepsilon+$ subj. en

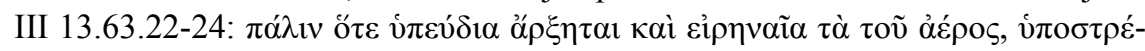

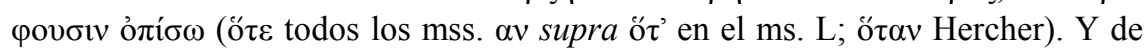

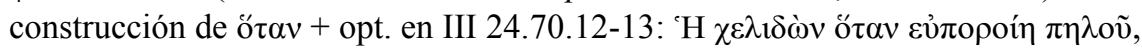

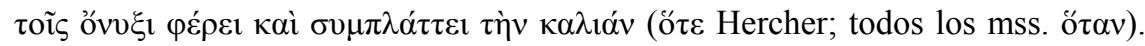

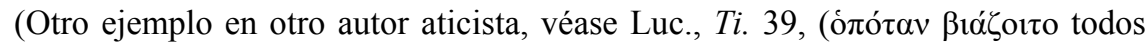

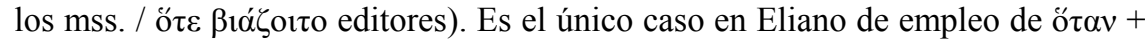
opt., pero el uso en la koiné y el consenso de los códices permite establecer sin

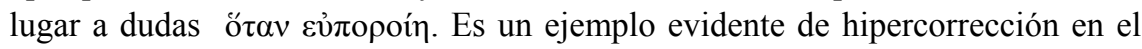
empleo de la partícula ớv. Se puede poner en relación, tal vez, el hecho de que en este autor ö $\tau \alpha v$ es la conjunción temporal más usada, la utiliza en 224 ocasiones (61,53\% del total de las temporales), mientras ö $\tau \alpha v$ aparece en 26 ocurrencias (7,14\% del total de las temporales). La explicación acertada es que en la koiné

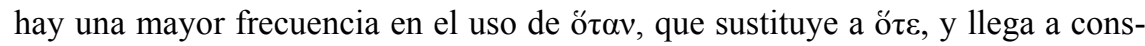
truirse también ö $\tau \alpha v$ con indicativo (véase, Blass-Debrunner §382.4; Cirac $\S 783)$.

III 26.71.21-24. Se está refiriendo a la abubilla en este capítulo. El texto: $\kappa \alpha i$ vं

23 La norma ática para expresar "repetición” emplea el subj. con ớv, cuando la oración temporal y la principal expresan una situación repetida o general, y están referidas al presente o al futuro (la partícula está ausente a veces en Homero, en la poesía y en Heródoto); este uso del subjuntivo con ớv se da incluso cuando hay un tiempo secundario en la supraordinada. El predicado verbal se expresa en opt. sin ớv cuando la oración temporal indica una situación repetida, se refiere al pasado o es potencial. Según la conjunción empleada y el valor aspectual de los verbos principal y subordinado, la subordinada es anterior, simultánea o posterior a la supraordinada. Véase, entre otros, Crespo 2003, §§ 37.3.3. y 37.3.4. 


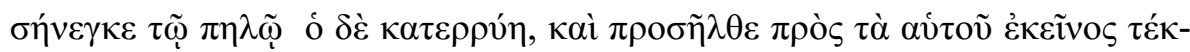
$v \alpha$.

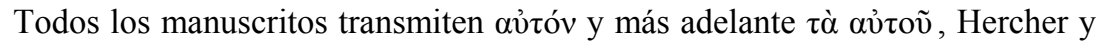

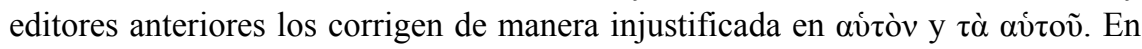
la koiné empleada por Eliano el pronombre ả̉ó́ se estaba usando con mucha frecuencia en vez de la forma avi $\tau$-, debe conservarse la lectura de los códices

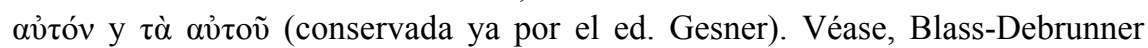
$\$ 278$ y 283; Mayser II 2, 71 ss.; Moulton I, p. 87; II, pp. 180-81. El pronombre reflexivo va abandonando algunas de sus funciones originales y éstas pasan a los pronombres personales simples, en los textos de la época helenística e imperial y en el Nuevo Testamento ${ }^{24}$.

III 26.71.26-29. Y más adelante en el mismo capítulo referido a la abubilla. ó

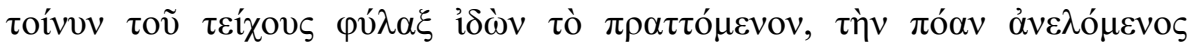

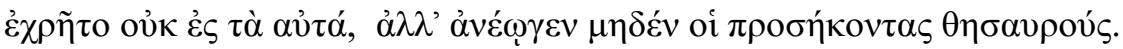

Todos los códices transmiten ảvoír $\omega v$, Hercher y editores anteriores lo modi-

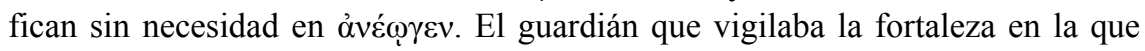
estaba empotrado el nido, al ver que volvía a estar accesible el agujero de entrada, apoderándose de la hierba que utilizaba la abubilla para disolver el barro, "no

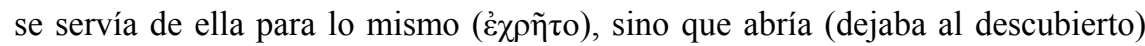

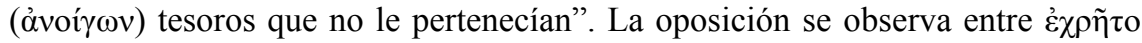

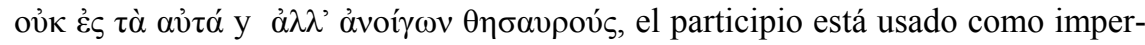
fecto de indicativo, en paralelo al imperfecto غ̇ $\chi \rho \tilde{\eta} \tau o$. Se trata del uso del participio en vez de verbo en forma personal; ésta es una estructura sintáctica muy frecuente en la koiné, en los textos literarios en prosa, construcción considerada muy elegante por los aticistas, a modo, tal vez, de un giro poético (ya que es empleada en poesía épica, desde Homero hasta los Lithika órficos), y, sin embargo, es una de las que más se han modificado debido al empeño de editores y críticos en imponer las normas del ático clásico, y corregir el texto modificando el participio en forma personal. Es frecuente en la koiné encontrar un participio unido por conjunción a verbum finitum ${ }^{25}$.

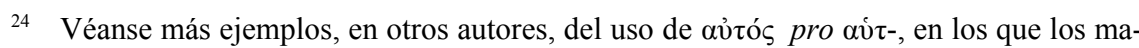

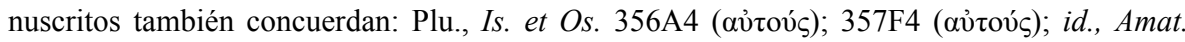

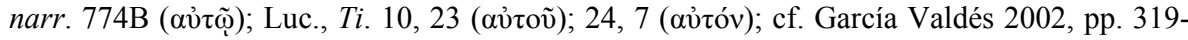

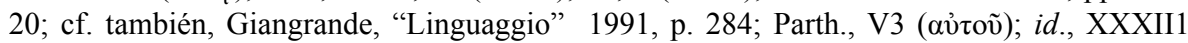
$(\alpha \hat{\tau} \tau \tilde{\omega} v)$.

25 Se encuentra ya en Tucídides, I 57,1, véase, López Eire 1984, p. 255; cf. Cirac 1957, p. 598; Moulton-Howard 1986, pp. 428-429; Giangrande 1992, pp. 39-40; id., "Linguaggio" 1991, pp. 280-281; id., (1984) IV 6, p. 365; cf. García Valdés 1995, Is. et Os. 352A5; 370B1; 


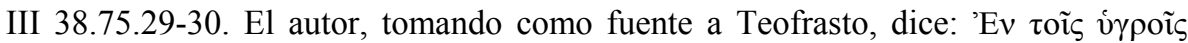

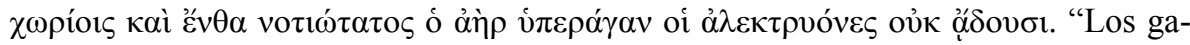
llos no cantan en los lugares húmedos y donde el aire está muy en exceso aguanoso"; la versión latina de Gillius: ubi coeli status valde pluvius est.

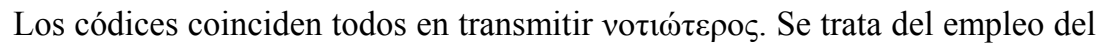
comparativo en vez del superlativo; es un uso muy común en la koiné y muy usado por los aticistas, tal vez, a modo de un empleo literario (cf. Schmid, Attic., op. cit., vol. V Sachregister, s.v. "Komparativ statt des Superlativs"). El fenómeno opuesto, superlativo en vez de comparativo, también se encuentra, muy probablemente, por hiperurbanismo ${ }^{26}$. El intercambio es un fenómeno típico de la lengua homérica y de los poetas helenísticos (véase, Giangrande, "Interpretazione", $o p$. cit., pp. 3-4); si su uso frecuente en la koiné puede entenderse como un empleo poético, un 'epicismo' buscado, o bien un vulgarismo, es imposible saberlo. Se constatan muchas ocurrencias de este fenómeno (cf. en el mismo libro, III

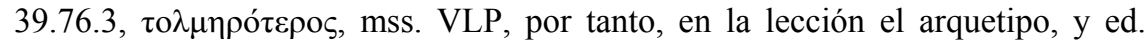

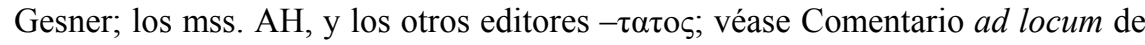

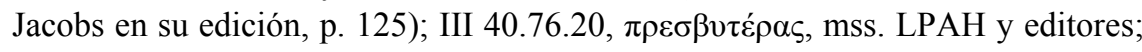
- $\tau \alpha \tau \alpha_{\varsigma} \mathrm{ms}$. V). Por tanto, se debe conservar la tradición unánime manuscrita vo-

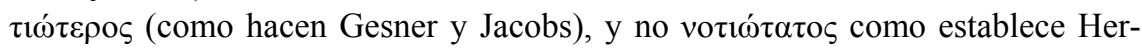
cher en ambas ediciones.

III 42.77.13-18. Se alaban las cualidades del calamón como una bella ave, que se sacrifica a sí misma si, después de su vigilancia, observa que una compañera hembra comete adulterio. Pasaje que presenta dificultad para establecer el texto del arquetipo debido a la defectuosa ortografía o, bien, mala

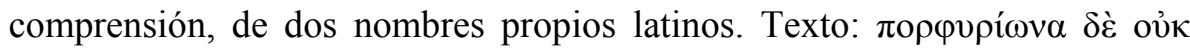

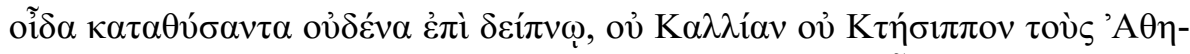

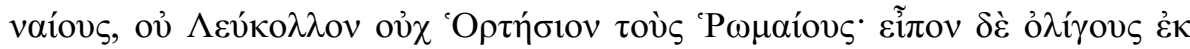

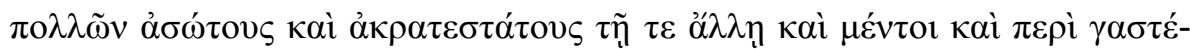
$\rho \alpha$. "No sé de nadie que haya sacrificado para comérselo un calamón, ni los atenienses Calias o Ctesipo, ni los romanos Lúculo u Hortensio ${ }^{27}$. Mencioné

371F6; 379A2, 383F4

26 Cf. Plu., Amat. narr. 774E2; si bien el superlativo es más frecuente, véase, Blass-Debrunner 1961, p. 244 (1) y (2); R. Adrados 1992, p. 350.

27 Calias es un rico personaje en cuya casa tienen lugar las escenas de los Simposios de Jenofonte y de Platón. Ctesipo fue un personaje frívolo, objeto de burlas de los poetas cómicos. Lúculo, del s. I a.C., fue proverbial por su riqueza; Plutarco en Vit. Lucull., 39 y 40, se

EMERITA (EM) LXXV 2, julio-diciembre 2007 pp. 199-224 ISSN 0013-6662 
a algunos de los muchos perdidos y muy inmoderados en otros placeres y $\sin$

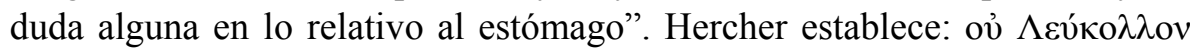

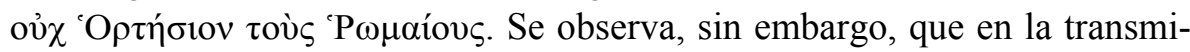
sión ha habido dificultades de diferente tipo.

De una parte, Eliano es un romano que escribe en griego y pudo tener ciertas dificultades para escribir los nombres propios latinos de Lucullus y Hortensius en griego, y desde el manuscrito del propio autor pueden arrastrarse variantes, o bien, desde el arquetipo medieval (cuando ya no se conocían a esos personajes), donde quedan notadas las dificultades en la comprensión de los nombres y se altera su grafía e incluso hay manuscritos que omiten el primero de ellos. Veamos los dos nombres y su transmisión:

1. Con referencia a ov̉ $\Lambda \varepsilon v ́ \kappa o \lambda \lambda o v$, así establecido por los editores Jacobs y Hercher; $\Lambda \varepsilon v ́ \kappa \circ \lambda \lambda$ ov establece el editor Gronovius. Los códices LPH omiten oủ

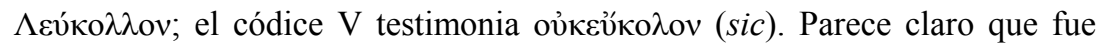
una mala lectura del escriba a partir de un oủ $\lambda \varepsilon v ́ \kappa o \lambda o v$ (con lambda no geminada) en el original: la falta de comprensión del nombre propio y la escritura continua ha dado lugar a la modificación de la primera lambda por kappa,

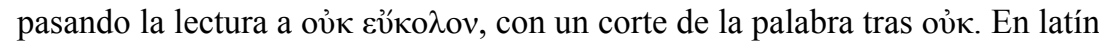
Lucullum, la grafía de la $u$ larga por el diptongo ov, o bien, $\varepsilon v$ griegos, es esperada, ya que el griego transcribe la $u$ larga latina por ov; debido a la evolución de los diptongos $e u$ y $o u>u$ larga, en latín; y la grafía de la $u$ breve por la omicrón griega, la $o$ breve originaria latina pasa a $u$ breve (véase Niedermann §33, 34, 28; Leumann §82(1.a-b); 80; 45; Bassols §126, 133; Lejeune $\S 241$. Sobre la vacilación de $l l / l$ en latín, véase, Niedermann $\S 68$; Leumann $\S 184 \mathrm{c}$; Bassols $§ 265$.

Una comprensión mala la confirma también el códice A: transmite a partir

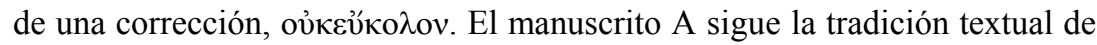
$\beta$, junto con los mss. LPH; en este pasaje A, por tanto, sería testimonio único de $\beta$, con una mala lectura bastante similar a la del ms. V. Al estar presente esta lectura en la tradición de $\beta$, muy probablemente la falta de comprensión ya se dió en el arquetipo. No obstante, el ms. A no es una prueba segura, ya que la segunda mano de $A\left(A^{v}\right)$, para suplir las partes que le faltaban, se sirve de un códice afín a $\mathrm{V}$, por tanto, pudo tener acceso a la tradición de $\mathrm{V}$ en esta lectura. La versión latina de Gillius vierte dos nombres, griegos, Calliam et Ethesippum (sic), y sólo uno de los romanos, Hortensium, Romanum (omite

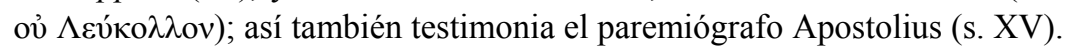

refiere a la famosísima lujuria de este hombre. Hortensio, famoso orador del s. I a.C., rival de Cicerón.

EMERITA (EM) LXXV 2, julio-diciembre 2007 pp. 199-224 ISSN 0013-6662 
Es claro que la falta de comprensión del nombre, Lucullum, ocasionó el

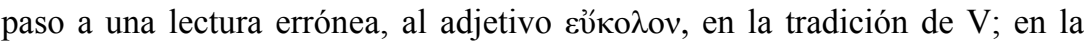
tradición $\beta$ (en LPH) ocasionó la omisión, aunque el texto griego siguiente en

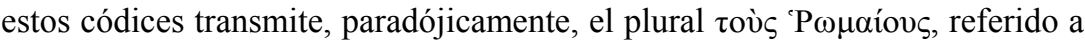
los dos nombres, y esto permite deducir que los dos nombres estaban en el arquetipo, ya que esto demuestra su presencia en las dos ramas de la tradición textual. El arquetipo medieval testimonia ya una defectuosa transmisión en el

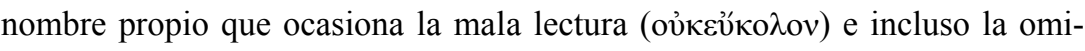
sión del nombre, aunque la adjetivación toùs $\mathrm{P} \omega \mu \alpha$ íovs, hace necesaria $\mathrm{y}$ testimonia la presencia originaria del nombre. Tras esta conclusión, es la mención del mismo nombre en Eliano ( $\Lambda \varepsilon v ́ \kappa о \lambda \lambda o \varsigma$, Var. Hist. XII 25) y en Plutarco (Vit. Cat. min., 10), la que permite restituir la lectura, oủ $\Lambda \varepsilon v ́ \kappa о \lambda \lambda o v$,

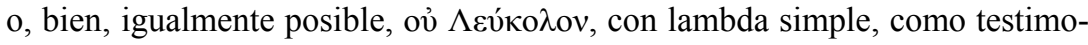

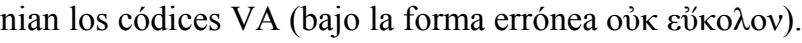

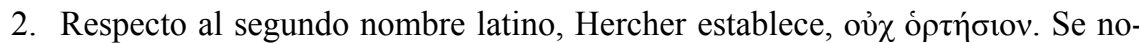
ta, de nuevo, la dificultad de escribir el nombre latino, Hortensius, en griego.

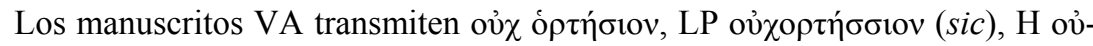

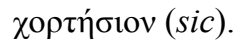

Se encuentra también este nombre en el libro quinto de la obra (V 21.120.9), en el pasaje en que se refiere al pavo real, como una de las más bellas y admiradas aves. Eliano menciona al romano Hortensio del que se dice que fue el primero en matar un pavo real para un banquete. Establece

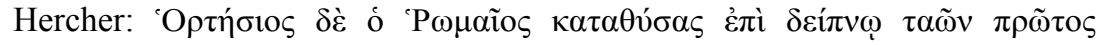

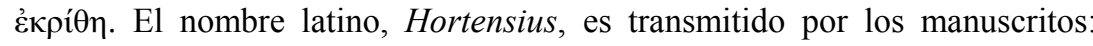

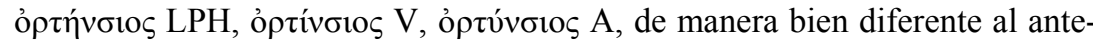
rior (III 42). Veamos en detalle.

a) El espíritu es suave en todos los mss., en el pasaje de V 21; en cambio, en III 42, los códices notan la aspiración, bien con el signo diacrítico (VA), bien por el efecto de la aspiración notada en la negación, ov̉ $\chi(\mathrm{LPH})^{28}$.

b) En el nombre latino Hortensius, al verterlo al griego, ya el propio autor debió tener dificultad, intentando, tal vez, acercarse lo más posible en la

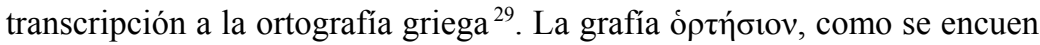

28 La vacilación en la notación de la $h$ (fricativa velar sorda) en latín desde s. II a. C. es frecuente en inscripciones y manuscritos (cf. Niedermann 1959, § 52; Leumann 1977 §178III.a. $\alpha$; Bassols 1992, §245).

29 La evolución del grupo $n s$ postnuclear en griego, ya desde el segundo milenio a.C., había evolucionado y había tenido lugar la simplificación de las antiguas nasales geminadas, que ocasiona el alargamiento de la vocal anterior, si era breve, según el fenómeno conocido

EMERITA (EM) LXXV 2, julio-diciembre 2007 pp. 199-224 ISSN 0013-6662 
tra en el pasaje III 42, notaría la evolución más afín al proceso de evolución esperado para el griego, con alargamiento de la vocal anterior (se puede ver para el latín, sobre el grupo -ns-, Bassols §146; Niedermann $\S 99$ y $36,2^{\circ}$; en Cicerón, Or. 159, cosul en vez de consul, hortesia en vez de hortensia, con o y e largas, respectivamente, y otros, con pronunciación del latín clásico). En el latín literario se restablece la $n$, manteniendo la cantidad larga de la vocal precedente. $\mathrm{Y}$ se atestigua el alargamiento de la vocal por transliteraciones al griego, como $\kappa \tilde{\eta} v \sigma o \varsigma=$ census. Así la grafía ỏ grupo $n s$ y el alargamiento de la vocal.

c) Se observa además el fenómeno de iotacismo (en V 21), al comparar los

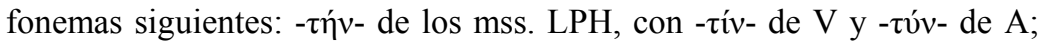
secuencia de fonemas en la que se da la confusión entre $\eta \mathrm{y} \imath$, y entre $v$ y ı, fenómenos fonéticos tardíos bien conocidos; muy documentados en las inscripciones y en los papiros, textos en los que se refleja la pronunciación en la escritura, y también aparecen en la koiné (cf. Lejeune $\S 225$; Mayser $\S \S 7.4 ; 13.2$ ).

d) Lo que se observa a partir de las variantes, si comparamos los dos pasajes (III42 y V21), es la vacilación en la grafía: 1. reducción del grupo - ns- con

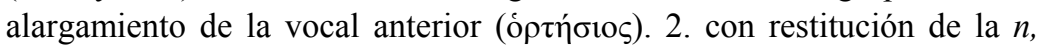

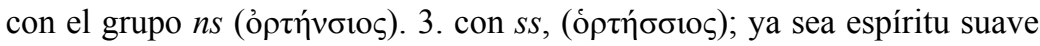
o fuerte. Muy probablemente el grupo -ss- intenta notar la pronunciación larga de la vocal precedente al desaparecer la $n$, o bien el estadio intermedio, y el grupo $n s$ restituye el originario de manera artificial en todas las

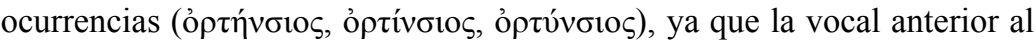
grupo - $n s$ - siempre es larga, pues el iotacismo revela que en estas tres variantes se parte de $\eta$.

La lectura ó alargamiento de la vocal precedente al grupo $n s$, la evolución común del grupo en latín y en griego y conserva la aspiración originaria del nombre. La variante ỏ ción, muestra el alargamiento de la $e$, que se da en griego y en latín cuando se reduce el grupo $n s ;$ y conserva el alargamiento de la vocal precedente cuando se restituye la $n$, fenómeno propio del latín.

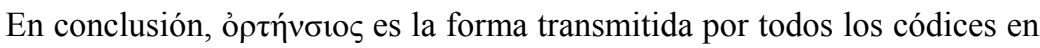

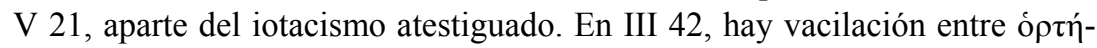
бıv (VAH) y ó

como "primer alargamiento compensatorio", véase, Lejeune 1987, §114.

EMERITA (EM) LXXV 2, julio-diciembre 2007 pp. 199-224 
garantiza la transmisión manuscrita, que refleja la vacilación que se encuentra en los textos literarios y en las inscripciones latinas: en III 42.77.15 ó En V 21.120.15, ỏ

III 44.77.24-28. En el fragmento se destaca la cualidad de la continencia en

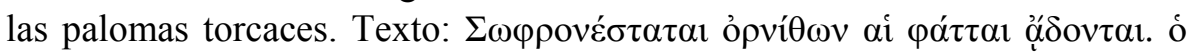

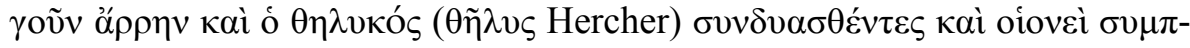

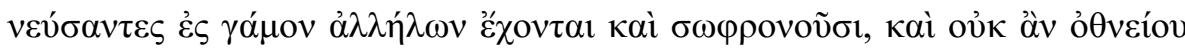

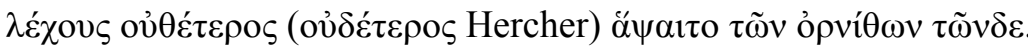

Es de destacar la partícula $\kappa \alpha i$, en cuarto lugar, que tiene valor consecutivo en la oración.

Veamos: Hay una acumulación de кai, bien empleados: el primero une dos

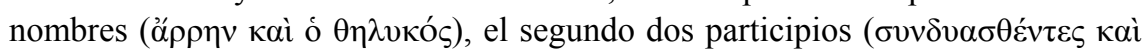
oioveì $\sigma 0 \mu \pi v \varepsilon v ́ \sigma \alpha \nu \tau \varepsilon \varsigma$ ), el tercero con su valor de coordinación de oraciones

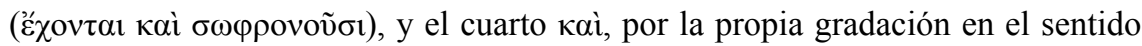
expresada en los términos y conceptos anteriores para poner de relieve la fiel unión de las dos aves, indica la consecuencia, el punto al que llegan de seguridad en su unión las aves. La versión latina de Gillius capta bien ese matiz consecutivo con las partículas adeo - ut: ex avibus castissimi (...), mutua consensione adeo ad stabile et certum connubium per summam castimoniam adhaerescunt, ut neuter alienum cubile attingat.

La transmisión manuscrita presenta variantes, tal vez por la falta de compren-

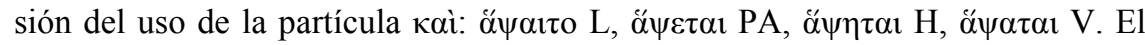
manuscrito $\mathrm{V}$ transmite un error en el verbo. La forma modal del predicado verbal de la consecutiva con indicativo expresa que la consecuencia es real y con optativo con ớv indica que la consecuencia es posible (cf. Crespo et alii, 41.2). La presencia de ớ justifica bien la elección del optativo ó $\psi \alpha \iota \tau$. Las variantes de los códices indican la libertad en el uso de ớv en la koiné; se emplea con frecuencia con el modo indicativo (cf. Blass-Debrunner $\$ 382$ (4); Moulton I, I, pp. 168 y 239; Mayser II 1, p. 273, n. 1), así la variante ó $\psi \varepsilon \tau \alpha ı$ de los mss. PA; las partículas modales en esta época tardía pueden asumir la función modal, que en la época clásica era inherente al modo (cf. Hoffmann, 336-337; R. Adrados, Sintaxis, 52930). El subjuntivo, al ir decayendo el uso del optativo, se convierte, simplemente, en modo de la subordinación, con o sin ớv, desplazando al optativo y al infiniti-

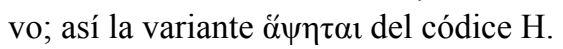

El empleo de кaì con variedad de usos, como enlace de oraciones, aparece ya desde el período clásico (cf., Th. I 20,3, valor consecutivo; cf. López Eire (1984) 153), y se incrementa en época tardía (cf. Blass-Debrunner $§ 442$ (2). 
Estas observaciones, por un lado, no han intentado ser una investigación exhaustiva de los problemas crítico-textuales y de interpretación de todo el libro tercero, sino mostrar cuánto debe y puede ser hecho para comprender bien el texto, eliminar correcciones y enmiendas y editar la obra de Eliano. He intentado, por otro lado, desarrollar y justificar las líneas metodológicas principales, ya que los textos literarios de la koiné requieren un tratamiento rigurosamente diferenciado, teniendo en cuenta la corriente literaria de la época, la evolución y el uso de la lengua, sus peculiaridaades fonéticas, morfológicas, sintácticas y léxicas de la prosa griega más tardía, y el uso del autor. 
NOTA BIBLIOGRÁFICA.

Ediciones:

1556 C. Gesner, Zurich, Editio princeps.

1611 C. Gesner, Ginebra (reedición de la anterior), acompañada de una versión latina de P. Gillius.

1744 Abraham Gronovius, Londres. Acompañada de una revisión de la traducción latina de P. Gillius. Versión latina que se reimprime por las ediciones posteriores hasta 1858.

1784 J. E. G. Schneider, Teubner, Leipzig.

1832 C. F. W. Jacobs, Jena. Con amplias notas críticas.

1858 R. Hercher, Didot, Paris. Acompañada de traducción latina y notas críticas al texto.

1864 R. Hercher, Claudius Aelianus I: De Natura Animalium Libri XVII. II Varia historia, epistolae, fragmenta, Leipzig, Teubner, 1864-66 (1971).

1959 A. F. Scholfield, Londres, reimprime la de Hercher, con traducción en inglés, Londres (reimpr. 1971).

1998 F. Maspero, reimprime la de Hercher, con traducción en italiano, Rizzoli, Milán.

Versiones en latin: Hay dos versiones de P. Gillius (Lugduni 1533 y 1565). La segunda de 1565 es del texto íntegro de la obra, sin añadidos.

Otros:

Bassols de Climent, M., Fonética Latina, Madrid 1992.

Bauer W., Griechish-Deutsches Wörterbuch, Berlín-Nueva York 1988.

Blass F. - Debrunner A., A greek grammar of the New Testament and other early christian literature, ChicagoLondres, 1961.

Cignac, F. Th., A Grammar of the greek papyri of the roman and byzantine periods, vol.I. Phonology, Milán, 1976.

Cirac Estopañán, S., Manual de gramática histórica griega. Vol. IV. Lecciones de sintaxis del verbo, Barcelona, 1957.

Crespo, E., Conti L., Maqueira, H., Sintaxis del griego clásico, Madrid, 2003.

Chantraine, P., Morfología histórica del griego, trad. esp., Reus 1974.

De Stefani, E. L., "I manoscritti della Historia animalium di Eliano", SIFC 10, 1902), pp. 175-222.

Id., "Gli Excerpta della Historia animalium di Eliano", SIFC 12, 1904, pp. 145-180.

Id., "Per 1'Epitome Aristotelis De animalibus di Aristofane di Bizanzio", SIFC 12, 1904, pp. 421-445.

Díaz Tejera, A., "Los modos griegos y la subordinación (subjuntivo y optativo)", Actas del VII Congreso Español de Estudios Clásicos I, Madrid 1989, pp. 73-92.

Foucault, J. A., Recherches sur la langue et le style de Polybe, París, 1972.

García Teijeiro, M., "Innovaciones sintácticas en la la koiné", Actas del VI Congreso Español de Estudios Clásicos I, Madrid, 1983, pp. 247-277.

García Valdés, M., Plutarco. De Iside et Osiride, Pisa-Roma, 1995.

Id., "Estudio crítico-textual de Adversus Indoctum de Luciano", EMERITA 65, 1997, pp. 65-75.

Id., "Estudio crítico-textual de El arte del parasitismo de Luciano", EMERITA 69, 2001, pp. 225-240.

Id., "Notas crítico-textuales a Timón o El Misántropo de Luciano", en Scritti in onore di Italo Gallo, a cura de Luigi Torraca, Nápoles, 2002, pp. 315-327.

Id. "Ciencia y moral: Eliano desde Aristóteles y a la luz del estoicismo y la 'zoofilia 'moderna”, EMERITA 71, 2003, pp. 1-50. 
Id., Luciano. Obras. Vol. VI, Introducción, Texto griego, Traducción y Notas, C.S.I.C., Alma Mater, Madrid, 2004.

Giangrande, G., "On the Text of Antoninus Liberalis”, en Athlon. Satura Grammatica in honorem F. R. Adrados, II, Madrid, 1984, pp. 363-372.

Id., "Interpretazione di testi poetici ellenistici", Siculorum Gymnasium XLII nn. 1-2, 1989, pp. 3-44.

Id., "Linguaggio e struttura nelle Amatoriae narrationes”, en Atti del III Convegno Pluatracheo, Nápoles 1991, pp. 273-294.

Id., Plutarco. Narrazioni d'Amore, Nápoles, 1991.

Giangrande, "La lingua dei Moralia di Plutarco: normativismo e questioni di metodo", en Strumenti per la recerca plutarchea, Nápoles, 1992, pp. 29-46.

Hoffmann, O.-Debrunner, A.-Scherer, A., Historia de la lengua griega, trad. esp., Madrid 1973.

Kühner R., Ausführliche Grammatik der Griechischen Sprache, II2, Hannover-Leipzig, 1904.

Lambros Spyridon P. (ed.), Excerptorum Constantini De Natura Animalium Libri Duo. Aristophanis Historiae Animalium Epitome. Subiunctis Aeliani Timothei Aliorumque Eclogis, Berlín, 1885.

Lasso de la Vega, J. S., "Algunas reflexiones sobre la crítica textual griega”, en A. Martínez Díez (ed.), Actualización científica en filología griega, Madrid, 1984, pp. 145-162.

Lejeune, M., Phonétique Historique du Mycénie et du Grec ancien, Paris, 1987.

Leumann, M., Latinische Laut- und Formen-Lehre, Munich, 1977.

Liddell H. R. - Scott R., Greek-English Lexicon, At Clarendon Press, Oxford 1968.

López Eire, A., "Tucídides y la koiné”, Athlon. Satura Grammatica in honrem F. R. Adrados, Madrid 1984, pp. 254-262.

Mayser E., Grammatik der Griechischen Papyri aus der Ptolemäerzeit, II,III,IIII, II1, II2, II3, Satzlehre, Berlín-Leipzig, (reimpr.)1970.

Moulton, J. H., A Grammar of New Testament Greek, vol. I. Prolegomena, Edimburgo, 1988.

Moulton J. H. - Howard W. F., A Grammar of New Testament Greek, II, Accidence and Word-Formation, Edimburgo, 1986.

Niedermann, M., Phonétique historique du latin, Paris, 1959.

Rodríguez Adrados F., Nueva sintaxis del griego antiguo, Madrid, 1992.

Schmid W., Der atticismus in seinen Hauptvertretern. Von Dionysius von Halikarnass bis auf den zweiten Philostratus, vols. I-IV, Register, vol. V, Stuttgart, 1887-1897 (reimpr. Hildesheim, 1964).

Stephanus H., Thesaurus Graecae Linguae, París, 1572 (reimpr., Graz 1954).

Veitch W., Greek verbs irregular and defective, Hildesheim 1967.

Waszink, J. H., "Osservazioni sui fondamenti della critica testuale”, QUCC 19, 1975, pp. 7-24.

Con arreglo a las normas editoriales vigentes para las publicaciones periódicas del CSIC, se hace constar que el original de este artículo se recibió en la redacción de EMERITA en el primer semestre de 2007, siendo aprobada su publicación en ese mismo período (18.01.07 - 21.03.07) 